\title{
Analysis of "Chinglish" Phenomenon in the Translation of Chinese Public Signs
}

\author{
Luyao Han \\ Department of English, Shanxi Normal University, Linfen 041000, China
}

\begin{abstract}
Public signs nowadays can be seen everywhere and applied in various public areas, the purpose of which is to provide some necessary indicative information for the international tourists or workers, facilitate their life and work, and also attract foreign investments. However, not all the bilingual public signs are translated appropriately, the quality of current translation is not very satisfactory owing to some internal and external reasons, thus the consequence of this inappropriate language using in public signs brought about the so-called Chinglish phenomenon, Chinglish is that misshapen, hybrid language that is neither English nor Chinese but can be described as English with Chinese characteristics, usually is unintelligible to the foreigners, which hinders the development of translation for communicating with foreigners. The thesis mainly concerns the causes of the emergence of Chinglish public signs which will be discussed from the cultural and linguistic dimensions in terms of various examples, the rest of the content will talk about the normal standard of Chinese-English sign language translation for eliminating Chinglish and attaining an unimpeded and efficient translation.
\end{abstract}

Index Terms - public signs, mistranslation, Chinglish phenomenon, translation standard

\section{INTRODUCTION}

Chinglish refers to the improper English using by Chinese learners due to the influence of mother tongue, thus some misshapen Chinglish form which contains the Chinese rules and habits has emerged in the process of English application, it does not fully comply with the rules of English language, more or less with Chinese cultural thinking habits. Chinglish can be viewed as Pidgin language, which refers to an English expression featured by the widely usage of Chinese grammar and word formation. Public signs, such as station name, road name, or indicators which involved in accommodation, travel, entertainment and shopping, such as hotels, restaurants, metro, hospitals, shopping malls, museums, etc. As an important indicator of social environment of city, all of which can be seen as the face of a city, a business card of a city, and a symbol of urban civilization. In order to truly realize the internationalization, the translation of the language must strive to be precise, concise and unified so as to convey the information accurately and communicate effectively with the outside world. The nonstandard language form can easily cause misunderstanding and confusing thoughts, it will seriously affect the economic and cultural exchanges with foreign countries.

The English translation of Chinese public signs has always been a focus in the field of translation, the public sign is a very unique type of writing, which has its own language characteristics, according to the academic field which has once made an agreement that the public sign has four functions: directing, prompting, restricting and compelling function (Halliday, 1994). According to He Gengyun (2006), the content of the public sign should be short, concise and comprehensive which involves sociology, psychology, linguistics, pragmatics and many other issues. It is necessary to achieve both language equivalence and cultural equivalence, in another words, the translators should make the English target signs much easier and accurate for readers to understand, which will absolutely increase the difficulty of translation. The translation of Chinese into English has become the most frequent sub-field of chinglish due to inattentive supervision of the government. To sum up, Chinglish in public signs translation can be divided into the following two categories.

\section{The AnALYSis OF “Chinglish” From the LingUistic Dimension}

\section{Improper meaning}

First of all, due to the existence of polysemy in English, if the translator is not clear about the meaning of the single word, the meaning of the whole text may be inaccurate. As a sign in a park “游客止步” translated into “tourist stop the steps", which is in accordance with the Chinese word order, it is just the word for word and sentence for sentence translation, the translator has not clear about the usage of the word "stop", it means stop, but this stop refers to the action. For example: "please stop, no entrance (车辆免进)! stop on red (红灯亮, 停一停)! Stop when red light flashes

(红灯亮, 勿前行)! Stop, look and listen (小心来车)! Stop after last rinse (清毕即止)!” (Luo Li, 2006, P.67). The meaning of these Chinese words is not to stop or stay here, but not enter or close to here. The correct translation should be: “No admittance" (Dai Lv, 2005, P.40). Another example: “农展桥” mistranslated into "NongZhan Bridge”. The translator only considers the problem from the perspective of the literal meaning of English language, which does not 
take into account the communicative intention and the connotative meaning of the linguistic sign. In English, bridge should be the concept of "water bridge", and “立交桥” refers to the important traffic junction of the city which has upper and lower layers, it the land bridge with no mutual interference among the branches, English translation should be "overpass" or "flyover". Therefore, it should be translated as "NongZhan overpass" (Xu Jiao, 2008, P.141). Secondly, translators who have little vocabulary or do not understand their own language habits are likely to confuse the denotative meaning of words, that is to say, an English word with extensive meanings can be used to express the words with many denotative meanings, or using a English word which has a narrow meaning to translate Chinese words with extended meanings, such as “旅游箱包”, can be translated into "luggage”, it is absolutely inappropriate to have this literal translation “Tourist cases bags”. There are translators who translate “化妆品和香水” into “cosmetics and perfume”, in which the denotation of perfume is extensive, not only refers to “香水”, but refers to the whole category of products, including eau de toilette, eau de perfume, after shave, shaving balm, using "fragrances" to fully express the original meaning of 香水 is relatively acceptable.

\section{Confusion of part of speech}

Chinese is a kind of notional language, but English is a normative grammatical language, so a English word at different position in a sentence must use different parts of speech, this strict grammar rule which usually has a root based with different suffix behind it, the different suffixes are the indicators to form different words with different parts of speech. While in Chinese, the verbs and nouns can be changed according to the language environment, but the form is exactly the same. If translator has not manipulate the different grammar usage of parts of speech between two languages, the phenomenon of wrong “Chinglish” would be emerged easily. Such as “食品烟酒” translated into “food or smoke wine", it's an typical improper using of part of speech. “食品烟酒” actually refers to the store which sales goods, tobacco and wine, “烟” is a noun in English, but the translation of “烟” is translated into the verb "smoke（抽 烟) ”, so the literal meaning is completely changed. Therefore, the correct version should be "Food, Cigarettes and Liquor”. Another case is “输液大厅” in the hospital, which mistranslated into “infusion hall”, “输液” in the Chinese context can be generally used as a verb or a noun, but in here, “输液” should be a verb phrase rather than a noun modifier, though the form is the same, so the English translation should use the verb "inject" instead of the term "infusion". The correct translation should be "IV Room" (Huang, 2002, P.42).

\section{Literal translation}

Although some of the public signs are very correct in grammar and diction, but they do not conform to the idiomatic expressions of the target language. The phenomenon of literal translation is very common in the translation of public signs, which is not only greatly reduces the authority of public signs, but also makes jokes, so the public signs should never be translated literally according to the sample literal meaning of Chinese. For example: a road sign “注意安全, 坡 道路滑” is translated into “To take notice of safe, the slippery are very Crafty”, obviously, it is just a word for word translation, simply according to the Chinese order and pattern, if this English translation translated into Chinese, that is “注意保险箱, 湿滑的路是很狡猾的” (Song, 2007, P. 22), totally inconsistent with the original meaning of Chinese which will seriously confuse foreigners. Another example: in the elevator of a hotel with such tips: "Please leave your values at the front desk" or “please put valuables at the front desk”, the Chinese meaning should have been “贵重物品 存柜”, which would inevitably be interpreted as: Leave your values or your Life（要钱要命自己挑）or “此路是我开, 此山是我栽, 要想保性命, 留下买路财”. There are similar examples: an airport baggage Department has such a public signs: “We take your bags and send them in all directions (旅客的行李满天飞)". Who would dare to enjoy his consignment service? The correct reference can be:“Door to Door Service” (接受托运家门), or “We take your bags and send them wherever you go (您行至何处, 您的行李随至何处)”“禁止吸烟”, “禁止靠近”, and “闲人免进” can not be translated literally as“don't smoke", “don't close to" and "No admittance for Outsiders", but should be translated as "No smoking", "Keep out" and "Staff only"(Luo Li, 2006, P.66).

\section{Repetitive and verbose diction}

As we all know, public signs should be concise and clear, the usage of nouns, verbs, adjectives and adverbs vary from Chinese and English expression, so the way of repetition using is also different, Nouns can be frequently used in Chinese without any problem, while in English, the user often use pronouns, phrases, or omissions to avoid the repetition of noun phrases. In addition, we know that Chinese is concise and comprehensive, which occupies less writing space; while English think highly of the logic relationship, so the writing space is relatively large. If public sign violates the means of expression, the translation will be lengthy which cannot attain concise and comprehensive effect. Such as: “此处有炸药, 注意安全” should be translated as “Danger: Explosives” instead of “We have explosives here. Pay attention to your safety”. Another example, a sign in the park lawn“小草微微笑，请您走便道” was translated into "Little grass is smiling slightly, please walk on pavement", which was absolutely the Chinglish, complying with the English speaking habit, it can be simply translated into: "Keep off the grass". In addition, there is another kind of public sign indicating some warning and prompting information just for the local people. For example: “公路范围内禁止摆摊 设点, 堆放杂物和垃圾等”, which points to local people, the foreigners have little possibility to do this kind of things. Therefore, the translator can only convey a brief meaning displayed on the wall, thus instead of a verbose translation, a 
relatively vague expression can let the foreigners to understand and accept the statement: "No vendors on the roadside; Please keep the highway clean (保持公路卫生)”.

\section{The ANALYSIS OF “CHINGLiSH” FrOM THE CULTURAL DiMENSION}

\section{Different ways of thinking between China and the west}

Firstly, the different modes of thinking between Chinese and West are as follows: the difference between comprehensive thinking and analytical thinking, concrete thinking and abstract thinking, and forward thinking and reverse thinking. Generally speaking, Chinese people have strong comprehensive and concrete thinking modes, while the Westerners apparently equipped with analytical, abstract and reverse thinking modes. Because of the influence of the way of thinking on language use and language habits, it will cause a lot of Chinglish in the translation of public signs. As public signs in the park lawn, Chinese generally use some vivid expression like “小草青青, 足下留情” or “小 草也有生命, 请爱护它们”, however, the literal translation “The grass is alive. Please take good care of it” is grammatical but inappropriate form the perspective of English language using style, it should be translated into "Keep off the grass" or other clear expression (Wang, 2003, P.38). Another example is "no smoking" sign in the hospital. Most of the Chinese diction are lovely and polite, like “为了您和他人的健康, 请不要吸烟”, while English are more likely to use more simple words to express, like "no smoking", these two typical case are influenced by the different way of thinking between Chinese and English, which is likely to cause misunderstanding. Similarly, the translation of “公厕” into "Public Toilet" is also influenced by the way of thinking, it can only needs to be translated as "Restroom" or "Toilet" (Wang, 2003, P.39). Moreover, Chinese has always been a country with strict etiquette, while American countries think highly of personality and freedom, therefore, the criteria for accepting the public signs is also different, if the airport has a sign with English like: Passengers with bulky baggage or who are disabled or infirm must use the lift (携带大型手提行李或伤残体弱这, 请用升降机上下), what this sign originally intended for is out of kindness, it's an embodiment of care for the disabled or weak passenger, but the translation with a word "must" implies a strict regulation or order which absolutely change the good intention before, moreover, it seems like a kind of discrimination against disabled and weak foreign travelers. Public signs are not only an important means of external publicity, but also an important means for cultural and emotional communication. Therefore, the principles of politeness should be followed in the translation, which reflects human care and creates a harmonious atmosphere, as a prohibition in the public signs “禁止践踏草坪”, the most common translation into English is: “Do not tread on the lawn”. "Do not" belongs to the imperative mood in English which has a strong tone and often cause misunderstanding, but if the translation is "Take care of the lawn", the tone is appropriate and more acceptable.

The cultural differences between China and the West

Culture plays an important role in translation, as long as we understand and get familiar with the culture reflected and implied by a language, we can really learn and correctly master the usage of specific words, on the contrary, if we just have little understanding of the target culture, we can not accurately grasp the constraint mechanism in the process of mutual language exchanges, which would make many language errors, and thereby resulting in the deficiency of cross-cultural communication ability or the failure in the cross-cultural communication. Intercultural translation should not only stay at the semantic level, but should take into account the differences of different cultures. In order to achieve the optimal communicative effect, we should respect different cultural customs and cultural traditions in translation, cultural conflicts are often caused by ignorance of cultural customs, if the translation of “视顾客为上帝” is like "Treating the patient as god", it is a typical manifestation of neglecting cultural differences, in China, we are accustomed to call customers God, but from the perspective of Westerners, “上帝” is the God which for worship, it is sacred and inviolable, so the westerners feel uncomfortable when they see this public sign translation, the most appropriate translated version can be "The patient is our first priority" (Xu , 2000, P.67).

\section{The Normal Standard for English Public Signs Translation}

Translation involves many interlingual transfer which from form to content, from voice to meaning, from the idea to the expressions of feelings, from the language to the all-round and multi-dimensional cultural awareness. The primary condition for public signs translation is that the translators should be very versed in both source and target languages. Therefore, we should follow some standards so as to attain a logic and reasonable translated version, that is, we should comply with the original text editors' intentions, concise principles, international conventions and other related criteria of translation.

\section{Comply with the original text editors' intention and readers' language habit}

The English translation of Chinese public signs should comply with the editors' original expression, and pay attention to the readers' reaction or feedback, according to the features of public signs, the translation must be solemn and polite, concise and comprehensive, eye-catching and intelligible. In the process of translation, as long as the translators revolve around the readers, put the reader in the first position, and try to narrow the differences between Chinese and English diction in form and meaning, the consequence of translation may break the constraint of Chinese thinking modes and can make the translation more accurate and understandable. We found that Chinese public signs hardly consider the 
readers' feeling, too many mandatory diction appear in the public, most foreigners cannot understand and accept such inappropriate signs, so in the translation of such strong prohibitive Chinese public signs, we might as well change this mandatory expression into the expression with persuasive and euphemistic tone by taking some translation strategies. What we want to cope with is that the public signs translation should not only achieve the function of public signs but also the dissemination of Chinese culture.

\section{Comply with the standard of brevity}

The public signs are used for the general public, the wording should be concise, readable and intelligible, and oral expression should be equipped with strength and rhythm. For example, “在营业中”, English can only use the word “Open”. “停止收款”, Don't use “Stop cashier”, but “Closed”. This error is due to the emergence of mechanical translation of source language, translator does not have a careful analysis to consider the wording and ignore the cultural connotation and customs, the presentation is just a kind of mechanically mother tongue translation, that is the so-called Chinglish. The problem is that translator complicates the original simple meaning, which can not play the eye-catching and reminding role among the public. For example, the warning phrase “水情复杂, 禁止在湖中游泳” (The water under the lake is complicated please don't swim in the lake!), obviously, the original idea is to remind visitors to pay attention to safety, not to swim in the lake area, here we can translate it simply into "Danger!" or "No Swimming!". In this way, it is concise and eye-catching, and can play a good warning role. Therefore, if we want to make the translation of Chinese public signs more authentic, accurate, and want to convey information more effectively, we must follow the principle of brevity.

\section{The Abidance of the international conventions}

The abidance of the international conventions refers to that the translator should consider the educational level of the the general public and tourists and carefully select the related words in the public signs translation. According to the using environment and content, complying with international conventions also requires the interpreter to adopt many idiomatic international expressions to do the translation, which means that the translators can directly draw lessons from the relevant international English public signs which are widely used and recognized. Such English public signs translation can exert its specific functions effectively, such as: “禁用烟火”can not be translated as “No fire and no smoking”, the correct translation should be “No Smoking Or Open Flames (禁止吸烟，严禁明火)” (Yang, 2005, P.43), if there is no any fire fighting icon (禁止烟火), “No fire” is ambiguous, because this phrase also has the meaning of the prohibition of fire using. In addition, there are a lot of international fixed public signs, such as: Lost \& Found (失物招 领)、Quiet! No Smoking! (保持安静, 禁止吸烟)、Taxi Pick-up Point (出租乘车站点)、Not For Children's Use (儿 童禁止使用)、Departing Flight (出发航班)、Delayed (航班延误)、No Littering (请勿乱扔废弃物) and so on. We should comply with the international conventions in light of the specific situation and try to learn the widely used and recognized English signs flexibly.

\section{CONCLUSION}

The level of English public signs translation directly reflects the level of internationalization and the taste of a city. In fact, the main purpose of English translation of Chinese public signs is to facilitate foreigners, however, because of the incautious and unprofessional using, which gives rise to the fault in the translation practice and the phenomenon of Chinglish afterwards, in view of the translation problems existing in the city, it is necessary for all parts of society to recognize and improve the overall level of the English translation of Chinese public signs. With the development of China's opening to the outside world, there will be more cooperation between China and foreign countries, so "Chinglish" will become a problem we must confront, therefore, it will be quite responsible for foreigners if translators attach more importance on the public signs translation and correct them timely, which can show our country's strength as a cultural power and exert a good English environment among the public.

\section{REFERENCES}

[1] Dai Zongxian, Lv Hefa. (2005). The Research of Public Signs Translation. Chinese Translators Journal, 6, 40.

[2] Halliday, M.A.K. (1994). An Introduction to the Functional Grammar. London: Edward Arnold.

[3] He Gengyun. (2006). The Research of Current Situation and Translation Method of English Translation of Chinese public signs. Foreign language Teaching, 3, 37.

[4] Huang Xinqu. (2002). The Basic Skill of Chinese-English Translation. ChengDu: Si Chuan People's Publishing House.

[5] Luo Xuanming, Li Shiwang. (2006). Some Thoughts on the Public Sign Language. Chinese Translators Journal, 4, 66-67.

[6] Nord, Christiane. (2001). Translating As a Purposeful Activity Functionalist Approaches Explained. Shanghai: Shanghai Foreign Language Education Press.

[7] Song Hongbo. (2007). The Pragmatic Translation of Public Signs. Journal of WuHan University of Science and Technology, 2, 22.

[8] Wang Hong. (2003). Conforming to the Meaning and Context-From the perspective of text translation. Chinese Translators Journal, 1, 38-39.

[9] Xu Shanshan, Jiao Congcong. (2008). The Research of the Fault and Translating Strategies for Chinglish Public Signs. Journal of Southwest University for Nationalities, 10, 141.

[10] Xu Yanan. (2000). The Feature and Requirement for Diplomatic Translation. Chinese Translators Journal, 3, 67. 
[11] Yang Quanhong. (2005). The Analysis of Public Signs Translation. Chinese Translators Journal, 6, 43.

Luyao Han was born in ChangZhi, Shanxi in 1994. She received her bachelor's degree in English from QuFu Normal University. She is currently a postgraduates studying for her master's degree and majoring in Foreign Linguistics and Applied Linguistics in ShanXi Normal University. Her research mainly focuses on the applied Chinese-English translation and Sociolinguistics. 